\title{
Winners or Victims? Discussing Identity Tracking and Behavior Analysis in Next-Gen Video Games from a Digital Civil Rights Perspective
}

\author{
Stefan PIASECKI ${ }^{10}$
}

'Prof. Dr., University of Applied Science for Public Administration and Management of North Rhine-Westphalia, Germany

\section{Sorumlu yazar/Corresponding author:} Stefan Piasecki,

University of Applied Science for Public Administration and Management of North Rhine-Westphalia, Germany

E-posta/E-mail: stefan.piasecki@fhoev.nrw.de

Geliş tarihi/Received: 14.03.2018 Kabul tarihi/Accepted: 23.05.2018

Atıf/Citation: Piasecki, S. (2018). Winners or victims? Discussing identity tracking and behavior analysis in next-gen video games from a digital civil rights perspective. Connectist: Istanbul University Journal of Communication Sciences, 54, 141-162. https://doi.org/10.26650/CONNECTIST406162

\begin{abstract}
The purpose of this article is to apply societal discourses on 'big data' to the growing practice of the collection of individual information and behavioral patterns of video game players to create virtual player representations. Game developers make use of such data to enhance the gameplay experience, and publishers can learn more about their customers. This article explains technical backgrounds and reasons why developers and publishers have an interest in gathering such a vast load of data. It also explains server gaming and game metrics technologies, takes a look at methods of consumer research, and discusses a critical standpoint from a civil rights perspective. While single aspects of the topic like big data or data mining have been researched and discussed before, the fact that many of today's video games are constantly retrieving, collecting and maintaining personal data about the players to learn about their patterns of behavior had much less coverage thus far. From a civil rights perspective new dangers arise beyond the widely discussed topics of virtual violence or obsessive gaming and gambling. As a result, it highlights the necessity that modern computer game players should view themselves as vital parts of information networks and, in return for being entertained, provide important personal information that can help to make their individual behavior transparent and usable for third parties and probably information brokers. Not only do providers of games benefit from the socioeconomic information users give, but security agencies and human resource consultants also share a vital interest in any behavioural data that makes an individual become transparent and predictable. Intelligence services, corporations and social networks generate user profiles from data previously submitted during gameplay. This could have a significant impact on future job and life prospects and aid the economic and political control of individuals since character traits like cowardize or courage and sociality become traceable.
\end{abstract}

Keywords: Player profile analysis, game metrics, identity tracking 


\section{EXTENDED ABSTRACT}

The purpose of this article is to apply societal discourses on 'big data' to the growing practice of the collection of individual information and behavioral patterns of video game players to create virtual player representations. Game developers make use of such data to enhance the gameplay experience, and publishers can learn more about their customers. This article explains technical backgrounds and reasons why developers and publishers have an interest in gathering such a vast load of data. It also explains server gaming and game metrics technologies, takes a look at methods of consumer research, and discusses a critical standpoint from a civil rights perspective. For the monetization of video games, real-time analytics are extremely important, and this soon became the business of specialized companies, which act as service providers to many major publishing companies in the games industry. Leading game developers are now making more money from so-called 'player recurring investments' (or 'microtransactions') than from the sales of digital games.

While single aspects of the topic like big data or data mining have been researched and discussed before, the fact that many of today's video games are constantly retrieving, collecting and maintaining personal data about the players to learn about their patterns of behavior has had much less coverage thus far. Video games today analyze the behavioral and even emotional profiles of their individual users, making the planning and prediction of their next moves possible. In traditional software development a videogame had to be developed in an often visionary, forwardlooking manner based on past gaming and sales experiences. This process was constantly overshadowed by the risk of commercial failure. Today game development is increasingly becoming a real-time task and involves players in the development from an early stage on - either participating in Kickstarter or Crowdsourcing campaigns or as public beta-testers.

Cloud technologies make their data accessible to the publishers or developers, and keep them beyond the subsequent control and influence of the players. The latest generation consoles Playstation 4 and Xbox One work according to this principle. Even users of finally released products are still - often without their knowledge involved in active development as their data and activity patterns become analyzed. Players slowly slide into the role of sparring partners for developers. The reactions of the players, analyzed in real time, now form the basis for innovation and change. This 
means nothing less than that development tasks become delegated to the users, which in the past had to be done by the in-house product quality departments.

From a civil rights perspective new dangers arise beyond the widely discussed topics of virtual violence or obsessive gaming and gambling. Critically put, server games tie players temporary and emotionally to artificial worlds. At the same time they get analyzed by 'Game Metrics', leaving behind emotional and mental 'fingerprints' deep within the systems. Today, the gameplay of registered users is constantly being recorded, comprehensively and completely. The technical system knows who focuses on criminal acts in the game and to what degree, who likes to slaughter orcs or who uses which weapons, who kills just as many people as possible in an open-world-game, who decides to fight for certain army units or terrorist groups, or who plays a particular war scenario.

Collecting personal and emotional data to be able to actually understand the previously unknown entity 'player' is also what intelligence services have always been interested in. If traces of individual credit card or cellphone use lead criminals or security agencies onto the trail of individuals and if social networks are already extensively being used by HR accountants to sculpt a model of characteristics of applicants before they have even had the chance to show up by accessing and using data which such applicants might have posted or uploaded (or created by accident) years ago, what profile will videogamers leave behind, whose actions over all the years of gaming provide a near perfect psychological and emotional fingerprint?

As for any other personal information there is a huge demand of commercializing even the most inner thoughts of a person. As a result, it highlights the necessity that modern computer game players should view themselves as vital parts of information networks and, in return for being entertained, provide important personal information that can help to make their individual behavior transparent and usable for third parties and probably information brokers. Not only do providers of games benefit from the socioeconomic information users give, but 'invisible third parties' also share a vital interest in any behavioural data that makes an individual become transparent and predictable. Intelligence services, corporations and social networks generate user profiles from data previously submitted during gameplay. This could have a significant impact on future job and life prospects and aid the economic and political control of individuals since character traits like cowardize or courage and sociality become traceable. 


\section{INTRODUCTION}

For the monetization of video games, real-time analytics are extremely important, and this soon became the business of specialized companies like Burstly.com (founded in 2009, acquired by Apple in 2014), which act as service providers to many major publishing companies in the games industry.

Leading game developers like Ubisoft are now making more money from socalled , player recurring investments' (or ,microtransactions') than from the sales of digital games (McAloon, 2017). In the case of Ubisoft this meant a revenue of 175 million euros in the first two quarters of 2017 for player recurring investments against 168 million euros for digital distribution - an impressive share of $51 \%$ of total digital revenues. The same goes for Electronic Arts (Strickland, 2017). The number of games published in a non-physical form has increased significantly and with it the profit thus generated (Lewis, 2018).

This method of revenue planning based on customized game behavior is known as 'monetization pattern'. Such patterns of profit increasingly interfere with elements of a game such as functions, storyline or even the innovation of developers. Sales are determined by the development and application of successful profit patterns, not primarily by ingenious game ideas. These are in turn modifiable and can be integrated into the existing system or removed from it. The purpose is to attract the 'whales', players who become addicted by a game and who are wealthy enough to stay attached and pay for any upcoming enhancement. From the industry's point of view, it is the 'whales' who grant wealth and success, sort of,extremist' users who invest monthly from hundreds to several thousand dollars in their gaming pleasure (Carmichael, 2013):

The "whales" of the social-gaming world are a mystery to most of us. As the biggest spenders, they make up a tiny group (think about 2 percent of audiences) that drives most of the revenues for publishers of these games. (...) We know they play social games, but are they social? Are their habits casual or obsessive? What kind of people are they?

To find such whales and to keep them close means to feed their appetite properly and in the right manner. Big money being spent and earned quickly attracts shady characters and questionable business methods as in any other industry. International 
online games offer considerable potential for criminal activity (fraud, embezzlement, money laundering, illegal financing of terrorist activities through 'sham' online games). Security agencies have a keen interest in using the data to identify evidence of addiction patterns or signs of criminal behavior by gamers (Trend Micro ForwardLooking Threat Research Team, 2016).

Server-based video games are increasingly gaining ground and changing the markets: games are no longer just being played on a dedicated games console in front of the TV. In fact, these are more and more reduced to the role of just being a smart remote control. Expensive hardware at home provides the graphical representation, while international servers host the actual game. From there data is (temporarily) being stored and distributed. Video games today analyze the behavioral and even emotional profiles of their individual users, making the planning and prediction of their next moves possible.

So-called 'server games' (World of Warcraft being one of the most famous, but more and more other smaller and bigger games for all types and ages of players also now use this way of distribution (see: Itch.io, 2018) can no longer be delivered via physical media or entirely downloaded from App servers. Instead, they perform in varying degrees mostly or solely on servers of publishing companies. Such environments can either be called 'Server Based Gaming Systems' (SBGS) or 'Server Supported Gaming Systems' (SSGS). The difference lies in the role of the client terminals, which manage or control only a small part or almost nothing of the main program (SBGS) or maintain a greater degree of tasks and the creation of content under the server's administration (SSGS). The company GLI has tried to define appropriate international standards (Gaming Laboratories International [GLI], 2007, p. 10).

Unlike with physical products (on CD-ROM etc.) users here only buy usage rights limited by time or content. This method is seeing an increased use not only for games but also for complex application programs. Well-known manufacturers of anti-virus software like Kaspersky work with this distribution model, as do Microsoft or Adobe, whose creative programs such as 'Photoshop' can now only be obtained via the company's own 'Creative Cloud' ('Products', 2018). Also, Microsoft's productivity suite, Office 356' must be acquired as a license and, utilizing the local computer as an interface, uses many productivity features via the 'cloud'. The 'cloud' here describes 
the framework of server-based virtual data environments, which can be accessed from access points such as PCs, smartphones, etc. The location of the data, and rights to access as well as the quantity and quality of the programs and files being stored and processed are usually not manageable by the users or only to a very limited degree, as that might promote errors or even fraud (GLI, 2007, p. 16).

\section{Predictable and Transparent Player Profiles: Defining a Frame for a Balanced Discussion}

In order to be able to discuss the implications of users actually being forced to grant access to their data and habits of use, first different views for and against server or cloud technology need to be laid out before further arguments can be put into perspective.

Advantages of using digital platforms or cloud technologies are somewhat economical: If a product does not need to be distributed in physical form, all profits which were in the past narrowed by production, sales and marketing (eg by renting shelf space in the store), now remain with the developers or publishers. Server/cloud technology "provides on-demand access without the need of any human intervention" (Jaiganesh, Ramadoss, Kumar, \& Mercy, 2015, p. 24).

Users are freed from any hassles or technical problems: they no longer have to buy and install a product and take care of updates. This eases their lives, but on the other hand disaccustoms them from generating their own technical knowledge. Manufacturers of games and applications can adapt and change the software at any time, include new functions and test the reaction of the users by evaluating their server protocols. They ask questions like these. Is the new function well received? In what way is it used? Developers can react to customer requests almost in real time.

Initially this offers benefits for the players. If game tasks or missions appear to be boring to the players, they need to be changed immediately in order to keep up the interest. Otherwise players could stop playing and turn to other games. What developers find exciting might not meet the demands of players and this knowledge is vital. "Even balanced units sets can create an uninteresting game if it is obvious to the players what the optimal strategy is" (Mahlmann, 2013, p. 142). 
In traditional software development a videogame had to be developed in an often visionary, forward-looking manner based on past gaming and sales experiences. This process was constantly overshadowed by the risk of commercial failure. Today game development is increasingly becoming a real-time task. The consequences will be significant.

The traditional video game was designed, financed and marketed by a development team and its management or publishing partners. Customer responses were monitored in the first few weeks after release, before sales slowly declined and interest faded. Today players are often directly involved in the development from an early stage on - either participating in Kickstarter or Crowdsourcing campaigns or as public beta-testers. Even users of finally released products are still - often without their knowledge - involved in active development as their data and activity patterns become analyzed since "gamers are an extremely valuable - and largely untapped source of participation bandwidth" (McGonigal, 2012, p. 232).

Games are subject to a number of basic premises attributable to technology: according to Hunicke, LeBlanc and Zubek's MDA approach (Hunicke, LeBlanc, \& Zubek, 2004) games can be judged from the perspective of Mechanics, Dynamics and Aesthetics. While "Mechanics" represents the program code and the rules of the game and "Dynamics" describes the technical process of the running program as well as the process of the game, "Aesthetics" depicts what makes them "fun". In effect, the graphics, the sound, the game controls, the overall feel of a game become something that can be experienced emotionally. Järvinen $(2009$, p. 88$)$ calls this a "system behavior":

A video game's 'system behavior' consists of the execution and governing of rule procedures: adding or subtracting points, instantiating the behavior of artificial intelligence through virtual characters, triggering scripted events in the game world, judging a player's performance, and so on.

Customers (or players) experience the aesthetic components and develop the gameplay in accordance with the technical framework through their play. However the "system behavior" only shows the surface of the underlying technical systems and game rules and does not reveal them. In the past users could, to some degree, estimate the technical background using their own expertise, because they often 
knew about the specification of their hardware and had their own previous experience with games. On the one hand, installation, troubleshooting and applying patches was often annoying, but on the other hand it also led to a general understanding of the technical context: users were included in significant parts of a products' lifecycle.

By contrast, games that reside in the cloud today, are largely intransparent to end users. They cannot make any modifications and they can no longer patch or cheat. They are - and will remain - solely in their role as consumers. Fighting against outbreaks or misuse of features has even become an independent field of business. Manufacturers try to identify cheating players and exclude them from the game servers using security software such as Valve's Anti-Cheat System 'VAC' (Steam Support, 2017). Others lock cheaters down with identified fellow cheaters into limbolike "cheater levels" (Nye-Griffiths, 2014) or direct gamers' desire for "creative selfperformance" to dedicated in-game elements with which even further sales can be generated. Physical retail versions of games such as GTA V (Playstation 4, Rockstar Games, 2013) or Star Wars: Battlefront II (Playstation 4, Electronic Arts, 2017) only include some of the available missions and game modes. A large part of such games is only accessible when players register online and pay additional monthly fees. Further progress in the game only becomes available in exchange for ingame currencies / credits (Fulton, 2017) that need to be bought. The use and evaluation of the personal data and individual responses on the gameplay of users is part of the business model they cannot escape.

While visualization and the feeling of a game largely remains a similar experience to the player whether a game is running on the cloud or on a stationary device, for the developers everything changes in many ways.

A game 'happens' visually on the player's screen, but the computer acts only as a digital mediator between the input medium/local terminal and the administrative unit on the servers of the game's publisher.

Next to raising profits this means:

- every action of the player can be logged. The player and all his actions as well as utterances in chats are visible and transparent, due to a clearly identifiable person of a human player (including credit card account and postal address etc.). 
- because every action is recorded chronologically, actions and verbal utterances (chats) can be identified and analyzed by the minute which makes the prediction of reactions and emotional behavior foreseeable.

- players cannot only be monitored retrospectively but in realtime.

- as user behavior is analyzed, changes in the level of difficulty can immediately be implemented and new functions can be introduced as a test and then expanded upon acceptance.

While developers see these possibilities as chances to make games better or more balanced (Dawes \& Hall 2005, p. 278-280) they may not take privacy into consideration.

This results in a paradigm shift for game development. Players are no longer just customers, but (unasked and thus unintentionally) evolve into the role of partners in the development. In addition, it is no longer just the player who learns how to deal with a game. Traditional game-learning models (Garris, Ahlers, \& Drsikell, 2002, p. 441) saw the player being integrated and embedded in a "learning cycle". They measured their success with the realities of the game and planned their future steps based on the reactions of the game system.

This has now changed with "server games". Today players and developers act within separate learning cycles with interrelated intersections. Bruns applied the term "Produsage" on such collaborative development cooperations (using the example of The Sims: Bruns, 2008, p. 289). He wanted to emphasize the simultaneously performed roles of individuals as users and also producers.

Players slowly slide into the role of sparring partners for developers who, for their part, hardly ever have to (or even can) finish work and bring it to a final state, because systems constantly adapt to the changes in user behavior. The reactions of the players, analyzed in real time, now form the basis for innovation and change. This means nothing less than that development tasks become delegated to the users, which in the past had to be done by the in-house product quality departments. Factors that make a game interesting had to be evaluated by developers mainly through their own experiences or from reviews and reports in game magazines. They had to extract the "fun factors" of previously released games for orientation (Wang, Shen, \& Ritterfeld, 2009, p. 30). Direct feedback from players to developers in the form of reply cards, mailings or direct contact was an additional source, but this was quantitatively and 
qualitatively very difficult to assess. So there was always an "enjoyment gap between Game Developers and Players" (Wang, Shen, \& Ritterfeld, 2009, p. 28) - a fun or perception gap. This gap has been closed in favor of a direct and steadily flowing stream of feedback.

\section{Observations Below the Shiny Surface of a Game: Data Processing and Games Development}

\section{Game content is not only used for entertainment purposes, it also leads to a commercialization of the actions of users:}

'Server Games' support interaction via intense monitoring. Users play a game and do not realize that they are being carefully analyzed and are part of a test environment while solving a mission or fighting a new opponent. They consider themselves to be autonomous users of a game they have purchased, but at the same time they are being used to generate new insights that are not limited to quantitative aspects such as merely the number of captured objects in a game $\mathrm{o}$, but also to qualitative methods that detect and analyze their emotional states and changes in consciousness (Mahlmann, 2013, p. 34).

Apps as well as games are no longer designed from scratch and then programmed over years before they can be put on the market. In their early days they often first appear as mini-games on the Internet in a greatly reduced form and can be played for free or for very little money while in the background new features are being applied step by step to the basic structure (Woolridge \& Schneider, 2010, p. 107). Even the once-important and sometimes well-known individual game developers themselves become interchangeable. Manufacturers become independent of individuals in the development as well as of certain user groups and target audiences, because by adapting the parameters of a running game and applying them to a different version with a new storyline etc. new audiences can be reached more easily than by an entirely new and risky development.

Users' input and data are vital for any test department. According to developer Jonathan Dankoff (Assassin's Creed, Ubisoft, 2010), they help with their game actions to improve, stabilize and expand the game as well as providing information that will feed into the development of upcoming games (Dankoff, 2014): 
If you play videogames while connected to an online service, there's a good chance someone is paying attention. At Ubisoft, we have a set of tools called DNA which use tracking data from multiple sources in order to allow us to examine telemetric data of how players are experiencing our games. We are able to track players in both production, and in post-launch. Production tracking is used to give insight on the game in progress of being made and allow designers to adjust the gameplay between playtests. Post-launch data is used for a wide variety of things: improving the game with a patch, helping to orient expansions and downloadable content for the game, and to advise the creators of the next game in the brand, or even other brands.

Server games use the reactions of players, adapt the game accordingly, and thus create a form of 'interactive relationship' between players and games. But while game and player are known, the creator of the game remains unknown and invisible.

The comprehensive analysis of the player's behavior is therefore a specific part of modern game development, which is becoming increasingly costly and therefore increasingly depends on making the game experience as user-oriented as possible (Mahlmann, 2013, p. 142):

\footnotetext{
Eliminating inferior choices and dominant strategies serves the goal of allowing a less predictable gameplay, without randomising the course of the game where the players' moves have no impact on the game. (...) Game mechanics should provide and encourage interesting games where players increase their chances by employing the right strategy rather than just pure randomness. Our assumption is that a game is interesting if it keeps a player engaged in conflict. One aspect of engaging conflict is its outcome, i.e. who will win or lose.
}

Only on the basis of these inital insights, can the development team expand and an early version evolve into the bigger version of the final game. Game environments that are able to adapt to players' actions and the changes of their behavioral patterns can remain attractive and demanding for a long time. Playing time and quantitative figures inform about the acceptance of a game amongst its audience. McGonigal appears almost euphoric (and uncritical) on the 'Service Records' of Halo 3 (McGonigal, 2012, p. 95): 
In April 2009, Halo 3 players celebrated a collective spine-tingling milestone: 10 billion kills against their virtual enemy, the Covenant. That's roughly one and a half times the total number of every man, woman, and child on earth. To reach this monumental milestone, Halo 3 players spent 565 days fighting the third and final campaign in the fictional Great War, protecting earth from an alliance of malevolent aliens seeking to destroy the human race. Together, they averaged 17.5 million Covenant kills a day, 730,000 kills per hour, 12,000 kills a minute.

Collecting such figures is only possible through the concept of 'server games'. Any significant action can be evaluated and visualized here, namely, who uses which weapons, what is the hit/miss ratio, does one focus on the missions or simply attempt to destroy everything for the fun of it, at which point in the game world do the players run, where do they go slowly? Where are they hiding? Where do they die?

By changing the strengths and weaknesses of non-player characters (NPC's) as well as the framework parameters of a game while it is running on a server, user reactions become manipulable. The player in return contributes to game development (McGonigal, 2012, p. 102):

There are data visualizations of every possible kind: interactive charts, graphs, heat maps. They help you learn about your own strengths and weaknesses: where you make the most mistakes, and where you consistently score your biggest victories; which weapons you're most proficient with, and which you're weakest with; even which teammates help you play better, and which don't. Thanks to Bungie's exhaustive data collection and sharing, everything you do in Halo adds up to something bigger: a multiyear history of your own personal service to the Great War. (...) The moments all add up. The millions of individual personal service records taken together tell the real story of Halo, a collective history of the Great War. They connect all the individual gamers into a community, a network of people fighting for the same cause.

The industry derives data that represents the way players approach game elements such as opponents or other obstacles (Joorabchi \& El-Nasr, p. 300), data that, above all, becomes commercially viable. From video players' perspectives, their game becomes "real" and part of their own history. Teenagers can exchange combat experiences like war veterans. The game does not remain a game, it jumps into the real world (Thompson, 2007). 


\section{Game analysis and reaction protocols become vital parts of the development process. Inhouse beta-testing is being extended into the post-launch sphere of commercial use:}

In order to deliver exactly what users want and to turn away from the classic premise of "Guess - Ship - Pray" (developing what seems to be attractive, bringing it to the market and then hoping that it will be a success), game analytics are used to supervise the "metrics" of a game (Blackhurst, 2011). Here, all parameters of a running system are constantly logged and analyzed and made visually representable (Anonymous, 2012). This results in extensive tables of generated data as well as digital maps that show the focus of playful action: where do most players die, which missions seem to be desired the most, which objects in the game have a high status amongst players, how do players respond to upcoming challenges (Drachen, Canossa, \& Møller Sørensen, 2013, p. 285):

\footnotetext{
"There are many ways to work with and utilize this highly useful source of user behavior data both during production and post-launch and ours is just one of these. Apart from the differences between single and multiplayer games, the degree of non-linearity and whether the game in question supports a persistent world or not, game type is also highly important. (...) Even within the confines of the shooter genre, there are different approaches to game analytics, but there appears to be a general consensus that gameplay metrics mesh well with other user-oriented approaches for evaluating and testing games."
}

Only cloud technologies can make this data accessible to the publishers or developers, since they remain beyond the subsequent control and influence of the players. The latest generation consoles Playstation 4 and Xbox One work according to this principle. In addition, Xbox One's Kinect camera can also record players reactions (and its environment) in real time and make it available to the developer. This sparks some debate on whether there might be civil rights issues to be addressed like Xbox's spying on its customers (Keilman, 2016). In fact this was not just a new feature of a game console that only adds to the gameplay experience. Xbox's Kinect camera constantly monitored the living room of the players in order to detect (and identify) new players and to correctly transfer their moves into appropriate game actions. What might be helpful for game developers and uncritically received or even welcomed by them was an immense threat to surveillance for privacy advocates and civil rights activists (Kohler \& Rubin, 2013) until it was finally shut down officially for commercial reasons in late 2017 (Thomas, 2017). 
In addition to the mining and evaluating of quantitative data, qualitative aspects also become increasingly sought after. Next to 'data mining' it is now 'mail mining' or 'chat mining' that is trying to catch up with expressions of emotions and opinions of players. More complex games, unlike most apps with a rather simple game structure, require more interaction between human players. These, however, exchange information by traditional means of communication which require interpretation instead of just accumulation. To recognize and utilize them is, in the words of Jens Peter Jensen, to raise a "treasure cove of information" (Jensen, 2013):

That makes the chat and/or mail system an obvious target for data mining, It is however difficult to properly extract information from the chat, because a lot of manual (human) interpretation is needed. The simplest way is to set up a metric that searches for words or phrases (...) but it is better to be more specific, especially if the results have to be read by humans. (...) Generally, the more specific the search the more useful the results, and the more easily humans can engage the information in a meaningful way.

\section{By becoming transparent and predictable players create 'contrails' of their online socialization:}

Players experience a game as an unfolding sequence of missions and situations of tension and relaxation. Developers create it as a set of questions to the players to which they respond by their actions. The developers' intentions behind these "game questions" are generally not visible to the user. Players always solve their puzzles and tasks on the surface of the game world, their attention being focused mainly on them. Cardoso-Leite et al. report that "heavy gamers" are particularly focused on the game and get less disturbed by distractions than users of other media (social media, television, etc.). Their actions are focused solely on competing and to accomplish the given tasks or to fulfill missions (Cardoso-Leite et al., 2016, p. 220):

Action video games are fast-paced interactive systems that place a heavy load on divided attention, peripheral processing, information filtering, and motor control. There is also a large load placed upon decision-making via the nesting of goals and subgoals at multiple time-scales. Action video games - in contrast to other types of games such as life-simulations - have been shown to produce a variety of benefits in vision, attention and ecision-making (...). In the domain of attention, action video games have been shown to improve the top-down attentional system, which underlies abilities such as 
focusing attention on some elements at the expense of others (i.e., selective attention), maintaining attention over longer periods of time (i.e., sustained attention), and sharing attention in time, in space or across tasks (i.e., divided attention (...).

However, this would also make it possible to misuse the computing power of human "heavy players" during their extended online-times as contributors to a botnet that appears in the game as a complex puzzle, but actually uses the creativity of users to manipulate a complicated encryption mechanism. In the past so-called botnets have repeatedly alarmed the public because of the infiltration of malware into individual computers, turning them into "zombieŷ systems", and diverting computing capacity to other tasks (Arntz, 2016). Projects such as the 'SETI Discovery of Alien Life Program' are also using this crowd-sourcing method openly with the involvement of users who are interested in supporting the search for extraterrestrial life-forms (see McGonigal, 2012, p. 236; http://setistars.org/), as well as illegal spy networks whose originators often go undetected. The more somebody is focusing attention only on certain game or application content, the less he might become aware of being misused.

\section{Playing a video game reveals a lot of one 's own personality:}

Beginning with the choice of the game and its setting, then moving on to how the player deals with its content, is a highly individual practice. Nevertheless, playing a game for long used to be a purely private affair, a very intimate process. Whether someone in GTA: San Andreas spent time practising cycling, developing the game hero's muscles, or watching women perform table dancing in dodgy clubs remained a personal matter for the player alone or his or her closer social environment.

Today, the gameplay of registered users is constantly being recorded, comprehensively and completely. The system knows who focuses on criminal acts in the game and to what degree, who likes to slaughter orcs or who uses which weapons, who kills just as many people as possible in GTA, who decides to fight for certain army units or terrorist groups, or who plays a particular war scenario. As with online mail-order companies, all personal information can become the basis for submitting additional entertainment offerings and advertising. Similar analysis methods are used to optimize online video rental or media streaming. Users receive offers based on patterns of previous consumption, which can be traced and tracked 
by "Web Mining" (Srivastava, Desikan, \& Kumar, 2005). The goal is always to sell the customer the next desired product, if possible even before the customer actually feels the need for it. Combined with social networks, however, humans not only become transparent customer models, but also assessable in terms of their most private preferences and behavior patterns.

Today, server based systems are able to respond to user behavior by balancing a large amount of data while at the same time generating new data and content and controlling it. Users of server-based services help to create a personal 'contrail of their own online socialization', which can later be exploited through third parties and even syndicated by comparing information of different sources. Users stand no chance of becoming fully aware of how they get monitored.

The latest generation of video games (not to mention future games) 'makes' players transparent. The creators of these games also use players as 'affiliates' for development, they utilize them as information providers, they visualize their otherwise hidden intentions and emotions. Of course, all for the sake of a good gaming experience. Collecting all sorts of personal information creates the multi-dimensional virtual imprint of an individual, an image of the real user within the artificiality of the server, just as the players create Avatars for their real gaming purposes.

In this regard, Robinson speaks of an "evolution of analytics in gaming" and divides the previous development into three phases, of which the third phase is currently rolling (Robinson, 2016):

Deep Data - the combination of a large number of data points, incredibly fast database technology and multiple data sources - enables the gaming experience to be personalized for individual players within segments, based on their engagement and playing style.

The sometimes publicly expressed criticism of providers of 'loyalty programs' such as Payback was mainly directed at the collection and visualization of individual consumption habits. The public was afraid of the "transparent customer" (Hofacker, Malthouse, \& Sultan, 2016, p. 95):

The collection of Big Data has the potential to worsen consumer privacy concerns. The convenience and relevance of personalization carry with them serious privacy concerns 
(...). What's more, as we have described, there is an increasing variety of data sources and contexts. Further, the consumer is often not aware that data collection is taking place. The data sources include online navigation, and social media participation, but increasingly location data, data from mobile beacons and very intimate data that are generated in the loT [Internet of Things].

Games build up on this immensely without being equally publicly criticized. Game development becomes an evolutionary process to which players contribute by providing data and therefore influence the development. The implicit 'questions' of the game are answered by the players while at the same time they themselves become authors in a system whose actual creator is no longer clearly identifiable (Aarseth, 1997, p. 165). They are rewarded by hours of entertainment, but pay themselves with their money and a comprehensive personality profile.

\section{DISCUSSION AND CONCLUSION}

\section{Entertainer or observer?}

Critically put, server games tie players temporary and emotionally to artificial worlds. At the same time they get analyzed by "Game Metrics", leaving behind emotional and mental 'fingerprints' deep within the systems. Collecting personal and emotional data to be able to actually understand the previously unknown entity 'player' is what intelligence services have always been interested in. For years the USled "Fight Against Terror" has been based on collecting and analyzing online data. As DeRosa $(2004$, p. 5) stated:

Unlike our Cold War adversaries, the terrorists are loosely organized in a diffuse, nonhierarchical structure. We cannot rely to the degree we did in the Cold War on finding a relatively few rich sources of intelligence that will provide insight into capabilities, tactics, and plans. Although all traditional intelligence-collection methods remain important, understanding the terrorists and predicting their actions requires us to rely more on making sense of many small pieces of information.

If traces of individual credit card or cellphone use lead security agencies onto the trail of criminals and if social networks are already extensively being used by HR accountants to sculpt a model of characteristics of applicants before they have even 
had the chance to show up by accessing and using data which such applicants might have posted or uploaded (or created by accident) years ago, what profile will videogamers leave behind, whose actions over all the years of gaming provide a near perfect psychological and emotional fingerprint? Just as disreputable photos in social networks can cause serious problems for someone's reputation today and in the future, these individual online profiles will not simply disappear or go (let alone remain) unnoticed. As for any other personal information there is a huge demand of commercializing even the most inner thoughts of a person. Users of various online services will add up to the creation of an increasingly dense, contrail' of their online socialization, which in comparison with other profiles reveals and accumulates socioeconomic information and can then be exploited by companies like "Recorded Future" who try to make personal connections and individual relationships visible and foreseeable (Shachtman, 2010). So far there seems to be only little to none organized resistance from users as well as developers or publishers. We do not have to fear that the offenders of the future can be identified today, as the future visions of the book and film Minority Report feared (Robert K. Dick, 1956 / Dreamworks, 2002). Or does it?

In the everyday life of many people, decision-making situations in the present could have an impact on the future beyond what one can personally influence. Screening suitable applicants with near-intelligence resources is a profitable business (see for example the profile of Grieger-Langer, 2017). Decision-makers (as well as security services) want data that reveals everything about a person and thus use what these willingly publish elsewhere (and extract what they need from other sources). It is no surprise that particularly after the events of $9 / 11$ security agencies became more interested than ever in online data and personality profiles (RobertsWitt, 2002, p. 6).

However, this possibly means that people today may (or should) consider which game to play or not because it can affect their future image and personality profile and shape unsettling questions: Why did you, as a young adult, enjoy 3D shooters? Why did you prefer playing on the side of terrorist groups? Why did you browse for related videos? Why do you avoid tricky situations in adventure games? Are you easily scared or maybe not creative enough? Why do you react emotionally and get upset easily in busy situations and even exit a game in moments of frustration. Are you not stress-resistant enough? 
In addition to this, games can also record and analyze behaviour, How do people react to a specific message in a game? What happens to the dynamics of a group? How would they deal with boredom or, on the contrary, a sudden outburst of violence in a game or with frightening situations. Who in a group is facing the danger, or who is the coward? How do people organize themselves in a virtual world and subsequently (possibly) in the real world?

Questions about the individual's problem-solving competence, persistence and cognitive or mental stability can easily be distilled from recorded play reactions.

\section{Outlook}

Not only do video games entertain, they are also tools of education and a reflection of society. Surely, as feared by DeRosa in 2004, people can innocently get into the view of security services (p.14) because of their activities online. In countries organized by the rule of law, evidence brought forward by investigators and evaluated by independent courts decide about guilt or innocence. However, DeRosa also confesses that it is uncertain whether systematic errors would ever be corrected, and what those who are affected by such errors could do against them: "Although the technology exists to follow inaccurate data and correct cascading occurrences, it has not been a priority, and its implementation lags far behind the technology for collecting and analyzing data" (DeRosa, 2004, p.15).

Aside from any rules of law, in the gray-shaded realms ranging from legal information mining to illegal secret service methods which on-line dealers and game platforms are operating, whose affiliation to a national legal framework would often first have to be clarified, not to mention information brokers of any kind. In the meantime, it can not be ruled out that extensive records of individuals will be collected over years and prepared for later strategic use.

From DeRosa's point of view, a deeper understanding of the techniques, methods and limits of the procedures would be necessary for the political decision makers to avoid civil law implications (DeRosa, 2004, p. 23). It seems doubtful to what extent they do have the knowledge of, or even the interest in, keeping up civil rights for gamers. 
It appears to be highly necessary that gamers and developers enter into a debate on whether any personal information can be collected, and if so which information and for what purpose. Such a debate needs to be mediated by experienced civilrights activists and not left to publishers or politicians alone.

\section{Acknowledgements}

I am grateful to my former student Linn Kaßner-Dingersen. She was and is an important reader of my work and provided valuable feedback. I also thank Pınar Aslan and the team at Connectist for a truly professional and enjoyable cooperation.

\section{REFERENCES}

Aarseth, E. J. (1997). Cybertext: Perspectives on ergodic literature. Baltimore, MD: John Hopkins University Press.

Anonymous. (2012). The science of CS: Go heatmaps. Retrieved from http://blog.counter-strike.net/science/maps. html

Arntz, P. (2016). The facts about botnets. Retrieved from https://blog.malwarebytes.com/cybercrime/2015/02/ the-facts-about-botnets/

Blackhurst, J. (2011). JC2 point cloud visualisation, realtime [video file]. Retrieved from https://www.youtube.com/ watch?v=|xvr1Rgl_Qc\&feature=player_embedded

Bruns, A. (2008). Blogs, Wikipedia, second life, and beyond. New York, NY: Peter Lang.

Cardoso-Leite, P., Kludt, R., Vignola, G., Ma, W. J., Green, C. S., \& Bavelier, D. (2016). Technology consumption and cognitive control: Contrasting action video game experience with media multitasking. Attention, Perception and Psychophysics, 78(1), 218-241.

Carmichael, S. (2013). What it means to be a "whale" and why social gamers are just gamers. Retrieved from http:// venturebeat.com/2013/03/14/whales-and-why-social-gamers-are-just-gamers/

Dankoff, J. (2014). Game telemetry with DNA tracking on assassin's creed. Retrieved from http://www.gamasutra.com/ blogs/JonathanDankoff/20140320/213624/Game_Telemetry_with_DNA_Tracking_on_Assassins_Creed.php

Dawes, M., \& Hall, R. (2005). Towards using first-person shooter computer games as an artificial intelligence testbed. In R. Khosla, R. J. Howlett \& L. C. Jain (Eds.), Knowledge-based intelligence information and engineering systems ( pp. 276-288). New York, NY: Springer.

DeRosa, M. (2004). Data mining and data analysis for counterterrorism. Retrieved from https://cdt.org/files/ security/usapatriot/20040300csis.pdf

Drachen, A., Canossa, A., \& Møller Sørensen, J. R. (2013). Gameplay metrics in game user research: Examples from the trenches. In M. S. El-Nasr, A. Drachen \& A. Canossa (Eds.), Game analytics: Maximizing the value of player data (pp. 285-319). London, UK: Springer. 
Fulton, W. (2017). Do players really like loot boxes, or are games publishers forcing them on us? Retrieved from https://www.digitaltrends.com/gaming/do-players-like-loot-boxes/

Gaming Laboratories International. (2007). GLI standard \#21. Retrieved from http://www.gaminglabs.com/ downloads/GLI\%20Standards/GLI-21\%20v2.1.pdf

Garris, R., Ahlers, R., \& Drsikell, J. E. (2002). Games, motivation \& learning: A research and practise model. Simulation \& Gaming, 33(4), 441-467.

Grieger-Langer, S. (2017). Personal profile and resume. Retrieved from https://profilersuzanne.com/wp-content/ uploads/2017/06/Expos\%C3\%A9-Profiler-Suzanne-english.pdf

Hofacker, C. F., Malthouse, E. C., \& Sultan, F. (2016). Big data and consumer behavior: Imminent opportunities. Journal of Consumer Marketing, 33(2), 89-97.

Hunicke, R., LeBlanc, M., \& Zubek, R. (2004). MDA: A formal approach to game design and game research. Retrieved from http://www.cs.northwestern.edu/ hunicke/MDA.pdf

Itch.io. (2018). Top games with server based network players. Retrieved from https://itch.io/games/multiplayerserver

Järvinen, A. (2009). Understanding video games as emotional experiences. In M. J. P.Wolf \& B. Perron (Eds.), The video game theory reader 2 (pp. 85 -108). New York, NY: Routledge.

Jaiganesh, M., Ramadoss, B., Kumar, A. V. A., \& Mercy, S. (2015). Performance evaluation of cloud services with profit optimization. Procedia Computer Science, 54(2015), 24-30.

Jensen, J. P. (2013). Building tight games with game metrics (part 3). Retrieved from https://gameanalytics.com/ blog/building-tight-games-with-game-metrics-part-3.html

Joorabchi, M. E., \& El-Nasr, M. S. (2011). Measuring the impact of knowledge gained from playing FPS and RPG Games on gameplay performance. In J. Anacleto, S. Fels, N. Graham, B. Kapralos, M. S. El-Nasr \& K. Stanley (Eds.), Entertainment computing - ICEC 2011 (pp. 300-306). New York, NY: Springer.

Keilman, J. (2016). Is my Xbox spying on me? Retrieved from http://www.chicagotribune.com/news/ct-toysonline-spying-keilman-hf-0106-20160101-column.html

Kohler, C., \& Rubin, P. (2013). New Xbox one: Kinect-game. Life-WIRED Exclusive [video file]. Retrieved from http:// www.youtube.com/watch?v=Hi5kMNfgDS4

Lewis, L. (2018). Why investors need to rethink video game companies. Retrieved from https://www.ft.com/ content/b53d239e-503a-11e7-a1f2-db19572361bb

Mahlmann, T. (2013). Modelling and generation strategy games mechanics. Copenhagen, DK: IT University of Copenhagen.

McAloon, A. (2017). Ubisoft's, player recurring investment' revenues outpace digital game sales. Retrieved from https://www.gamasutra.com/view/news/309155/For_the_first_time_Ubisofts_microtransactions_ outearned_digital_game_sales.php

McGonigal, J. (2012). Reality is broken: Why games make us better and how they can change the world. London, UK: Vintage. 
Nye-Griffiths, D. (2014). Titanfall's anti-cheat system activates, is beautyful and hilarious. Retrieved from https:// www.forbes.com.com/sites/danielnyegriffiths/2014/03/27/titanfalls-anti-cheat-system-activates-isbeautiful-and-hilarious/\#c07b24035eb8

Products. (2018). Retrieved from https://www.adobe.com/products/catalog.html

Roberts-Witt, S. L. (2002). Data mining: What lies beneath? Retrieved from https://www.pcmag.com/ article2/0,2817,1162415,00.asp

Robinson, M. (2016). The game industry's shift to deep data. Retrieved from http://dataconomy.com/2016/02/ the-games-industrys-shift-to-deep-data/

Seti Stars (nd). Retrieved from https://setistars.org/

Shachtman, N. (2010). Exclusive: Google, ClA invest in "future" of web monitoring. Retrieved from https://www. wired.com/2010/07/exclusive-google-cia/

Srivastava T., Desikan P., \& Kumar V. (2005). Web mining: Concepts, applications and research directions. In W. Chu, T. Y. Lin (Eds.), Foundations and advances in data mining.(studies in fuzziness and soft computing)(pp. 275-307). Berlin, DE: Springer.

Steam Support. (2017). Valve Anti-Cheat system (VAC). Retrieved from https://support.steampowered.com/kb_ article.php?ref=7849-Radz-6869

Strickland, D. (2017). EA earns \$1.68 billion in microtransactions FY2017. Retrieved from https://www.tweaktown. com/news/57475/ea-earns-1-68-billion-microtransactions-fy2017/index.html

Thomas, S. (2017). Microsoft finally kills off support for the Xbox kinect peripheral. Retrieved from http://www. game-debate.com/news/23950/microsoft-finally-kills-off-support-for-the-xbox-kinect-peripheral

Thompson, C. (2007). Halo 3: How Microsoft labs invented a new science of play. Retrieved from http://www.wired. com/gaming/virtualworlds/magazine/15-09/ff_halo?currentPage=all

Trend Micro Forward-Looking Threat Research Team. (2016). Funding cybercrime: The hidden side of online gaming currency selling. Retrieved from https://blog.trendmicro.com/trendlabs-security-intelligence/ funding-cybercrime-the-hidden-side-of-online-gaming-currency-selling/

Wang, H., Shen, C., \& Ritterfeld, U. (2009). Enjoyment of digital games - what makes them "seriously" fun? In U. Ritterfeld, M. Cody \& P. Vorderer. (Eds.), Serious games. Mechanisms and effects (pp. 25-47). New York, NY: Routledge.

Wooldridge, D., \& Schneider, M. (2010). The business of Iphone app development: Making and marketing apps that succeed. New York, NY: Apress. 